Departement Pferde der Vetsuisse-Fakultät Universität Zürich

Direktor: Prof. Dr. med. vet., MS, Diplomate ACVS, ECVS

Jörg Andreas Auer

Arbeit unter der Leitung von Prof. Dr. Jörg Andreas Auer

\title{
Comparison of Computer Assisted Surgery with Conventional Technique for Treatment of Abaxial Distal Phalanx Fractures in Horses: An In Vitro Study
}

\author{
INAUGURAL-DISSERTATION \\ zur Erlangung der Doktorwürde der \\ Vetsuisse-Fakultät Universität Zürich
}

vorgelegt von

\section{Melanie Rossol}

\author{
Tierärztin \\ von Gehrden, Deutschland
}

Genehmigt auf Antrag von

Prof. Dr. Jörg Andreas Auer, Referent

Prof. Dr. Christoph Johannes Lischer, Korreferent 



\section{Meinem Vater}

Was lebt, ist unvertilgbar, bleibt in seiner tiefsten Knechtsform frei, bleibt eins und wenn du es scheidest bis auf den Grund, bleibt unverwundet und wenn du bis ins Mark es zerschlägst und sein Wesen entfliegt dir siegend unter den Händen.

\section{Friedrich Hölderlin}



Titel der Dissertation:

Comparison of Computer Assisted Surgery with Conventional Technique for Treatment of Abaxial Distal Phalanx Fractures in Horses: An In Vitro Study

Melanie Rossol, 2008

Departement Pferde der Vetsuisse-Fakultät Universität Zürich

Pferdechirurgie

Sekretariat: Frau Gabriele Schmid, E-mail: gschmid@,vetclinics.uzh.ch

\section{A B S T R A C T}

Objective: To (1) evaluate and compare computer assisted surgery (CAS) with conventional screw insertion (conventional osteosynthesis [COS]) for treatment of equine abaxial distal phalanx fractures; (2) compare planned screw position with actual postoperative position; and (3) determine the preferred screw direction.

Study design: Experimental study.

Sample population: Cadaveric equine limbs $(n=32)$.

Methods: In 8 specimens each, a $4.5 \mathrm{~mm}$ cortex bone screw was inserted in lag fashion in dorsopalmar (plantar) direction using CAS and COS. In 2 other groups of 8, the screws were inserted in opposite direction. Precision of CAS was determined by comparison of planned and actual screw position. Preferred screw direction was also assessed for CAS and COS.

Results: In 4 of 6 direct comparisons, screw positioning was significantly better with CAS. Results of precision analysis for screw position were similar to studies published in human medicine. None of evaluated criteria identified a preferred direction of screw insertion.

Conclusion: For abaxial fractures of the distal phalanx, superior precision in screw position is achieved with CAS technique compared with COS technique.

Clinical Relevance: Abaxial fractures of the distal phalanx lend themselves to computer assisted implantation of 1 screw in dorsopalmar (plantar) direction. Because of the complex anatomic relationships, and our results, we discourage use of COS technique for repair of this fracture type. 



\title{
Comparison of Computer Assisted Surgery with Conventional Technique for Treatment of Abaxial Distal Phalanx Fractures in Horses: An In Vitro Study
}

\author{
MELANIE ROSSOL, MedVet, DIEGO GYGAX, DrMedVet, JULIANE ANDRITZKY-WAAS, DrMedVet, \\ GUOYAN ZHENG, Dr.-ing, CHRISTOPH J. LISCHER, DrMedVet, MS, Diplomate ECVs, XUAN ZHANG, Ms, and \\ JOERG A. AUER, DrMedVet, MS, Diplomate ACVS \& ECVS
}

\begin{abstract}
Objective-To (1) evaluate and compare computer-assisted surgery (CAS) with conventional screw insertion (conventional osteosynthesis [COS]) for treatment of equine abaxial distal phalanx fractures; (2) compare planned screw position with actual postoperative position; and (3) determine preferred screw insertion direction.

Study design-Experimental study.

Sample population-Cadaveric equine limbs $(\mathrm{n}=32)$.

Methods-In 8 specimens each, a $4.5 \mathrm{~mm}$ cortex bone screw was inserted in lag fashion in dorsopalmar (plantar) direction using CAS or COS. In 2 other groups of 8, the screws were inserted in opposite direction. Precision of CAS was determined by comparison of planned and actual screw position. Preferred screw direction was also assessed for CAS and COS.

Results-In 4 of 6 direct comparisons, screw positioning was significantly better with CAS. Results of precision analysis for screw position were similar to studies published in human medicine. None of evaluated criteria identified a preferred direction for screw insertion.

Conclusion-For abaxial fractures of the distal phalanx, superior precision in screw position is achieved with CAS technique compared with COS technique.

Clinical Relevance-Abaxial fractures of the distal phalanx lend themselves to computer-assisted implantation of 1 screw in a dorsopalmar (plantar) direction. Because of the complex anatomic relationships, and our results, we discourage use of $\operatorname{COS}$ technique for repair of this fracture type.

(C) Copyright 2008 by The American College of Veterinary Surgeons
\end{abstract}

\section{INTRODUCTION}

A BAXIAL FRACTURES represent the most frequent type of equine distal phalanx fracture. ${ }^{1-5} \mathrm{Be}-$ tween 1992 and 2003, 44\% of distal phalanx fractures in 111 horses admitted to our hospital were abaxial in configuration.

Most abaxial distal phalangeal fractures have an intraarticular component, which promotes development of degenerative joint disease because of step formation and continuous motion during weight bearing. ${ }^{6-9}$ The abaxial position of the fragment, the size discrepancy between the parent bone and fragment, and lateral expansion of the hoof during loading may lead to increased fragment motion compared with axial fractures, expediting the development of degenerative joint disease. These fractures heal poorly often as a fibrocartilaginous nonunion, ${ }^{8,9}$ which contributes to prolonged convalescence. Synovial fluid movement during loading may further delay healing. ${ }^{5}$

From the Equine Department, University of Zurich, Zurich, Switzerland.

Study supported in part by AOVET, Winterthurerstrasse 260, CH-8057 Zurich, Switzerland.

Dr. Rossol's current address is Hofgut Albfuehren 12, D-79802 Dettighofen, Germany.

Address reprint requests to Prof. Joerg Auer, Dr Medvet Vetsuisse Faculty, Equine Department, University of Zurich, Winterthurer Str. 260, Zurich 8057, Switzerland. E-mail: jauer@vetclinics.unizh.ch.

Submitted January 2007; Accepted September 2007

(c) Copyright 2008 by The American College of Veterinary Surgeons

$0161-3499 / 08$

doi:10.1111/j.1532-950X.2007.00346.X 
In mature horses ( $\geq 3$ years) conservative management, which typically includes stall confinement and use of a full-bar shoe with quarter clips, rarely results in satisfactory healing. ${ }^{10,11}$ Thus, anatomic reduction and internal fixation of articular fractures of the distal phalanx using interfragmentary cortex screws inserted in lag fashion across the fracture to induce bony union is the preferred method of treatment. ${ }^{3,4,6-16}$ Compared with the axial fractures ${ }^{3,4,7-11,13-16}$ there are relatively few reports

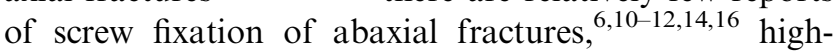
lighting the difficulty associated with repair of this fracture configuration. ${ }^{8,9,17}$

Determination of the exact location of the fracture plane is difficult with conventional imaging techniques. This makes it difficult to achieve perpendicular orientation of screws relative to the fracture plane. Other factors that make repair difficult are the poor visibility of the 3 -dimensional (3D) orientation of the fracture plane, ${ }^{16}$ the configuration and relatively small size of the palmar/ plantar eminence fragment, and the risk that the bone provides inadequate resistance to compressive forces exerted by the screw head during tightening. ${ }^{9,10,16}$ Additionally, the screw should be implanted midway between the solar surface of the distal phalanx and the joint and avoid penetration of the semilunar canal. ${ }^{8}$

Precise definition of the necessary screw length is almost impossible because of the dome-shape of the distal phalanx and the superimposition resulting from projecting a $3 \mathrm{D}$ object onto a $2 \mathrm{D}$ plane. ${ }^{18}$ Screw length can only be determined through exact tangential radiographic or fluoroscopic views of the exit point of the screw. ${ }^{16}$

Other hazards associated with this type of surgery are difficulties in exactly localizing the screw hole and in applying enough compression when tightening the screw. This can lead to displacement of the fragment and intraarticular gap formation as well as increase the risk of infection because of the approach through the heavily contaminated hoof wall. ${ }^{3,6,7,19}$ Postoperatively, osteolytic changes are consistently encountered around the implants. ${ }^{16}$ Such changes could be caused by implant loosening within the cancellous bone structure of the distal phalanx secondary to movement associated with normal loading and unloading the foot. Motion at the fracture line could also increase the risk of infection. More commonly, osteolytic changes reflect infection, which inevitably results in screw removal after 90-120 days. $^{3,7,9,14,16,19}$ For these reasons, surgical management of abaxial fractures of the distal phalanx is rarely attempted.

The development of computer-assisted surgery (CAS) in human surgery has opened new horizons in veterinary orthopedic surgery. Given the problems associated with conventional surgical repair of abaxial fractures of the distal phalanx we were interested in application of CAS to improve the precision of fracture repair. Thus, our aims were: (1) to evaluate CAS as a potentially superior surgical technique compared with conventional osteosynthesis (COS) repair for treatment of abaxial distal phalanx fractures; (2) to compare planned screw position with actual postoperative position; and (3) to determine the preferred direction of screw insertion for optimal fracture reduction and compression.

\section{MATERIALS AND METHODS}

Cadaveric horse limbs free of distal interphalangeal and distal phalangeal disease (determined by clinical examination) were used. Limbs were disarticulated at the carpometacarpal and tarsometatarsal joints, respectively. Paired forelimbs and hind limbs were randomly assigned to either CAS or COS groups, each consisting of 16 limbs (8 pairs). Sixteen sheets containing data on assignment to group (COS or CAS) and location of the fracture (lateral, medial), ensuring equal numbers of left and right limbs and lateral and medial fractures assigned to each group, were prepared before starting the study, placed in unmarked envelopes and sealed. As a new pair of limbs was selected, an envelope was opened and the instructions on the sheet were followed. Abaxial fractures of the distal phalanx were created using a chisel placed $2 \mathrm{~cm}$ lateral or medial to the extensor process at the coronary band (Fig 1). Fracture outcome was verified by fluoroscopy. For CAS and COS, $8 \mathrm{limbs}$ in each group were treated with a single $4.5 \mathrm{~mm}$ cortex screw inserted in dorsopalmar or dorsoplantar direction and the other 8 limbs had the screw inserted in a palmaro- or plantarodorsal direction.

\section{Basic Surgical Technique}

The hoof capsule was opened with a 10 -mm-diameter drill bit. Screw insertion in lag fashion was performed using standard technique ${ }^{20}$ The screw hole was prepared very carefully to prevent displacement of the fragment during screw tightening and to avoid subsequent loss of anatomic reduction and associated step formation in the joint. Good interfragmentary compression had to be achieved. We refined the technique by use of a torque-indicating screwdriver for final manual screw tightening to determine the maximum torque applied to the screw.

\section{$C A S$}

A detailed description of CAS technique has been reported. ${ }^{18}$ The navigation system is an active type, meaning that all instruments communicate with the system through light-emitting diodes (LEDs). The camera registers the LED-signals and projects them onto the monitor. The Dynamic Reference Base (DRB), which is attached to the bone to be operated on, contains identical LEDs and therefore allows data acquired through the SIREMOBIL Iso-C ${ }^{3 \mathrm{~d}}$ to be combined with the actual anatomy of the patient through a registration-free 


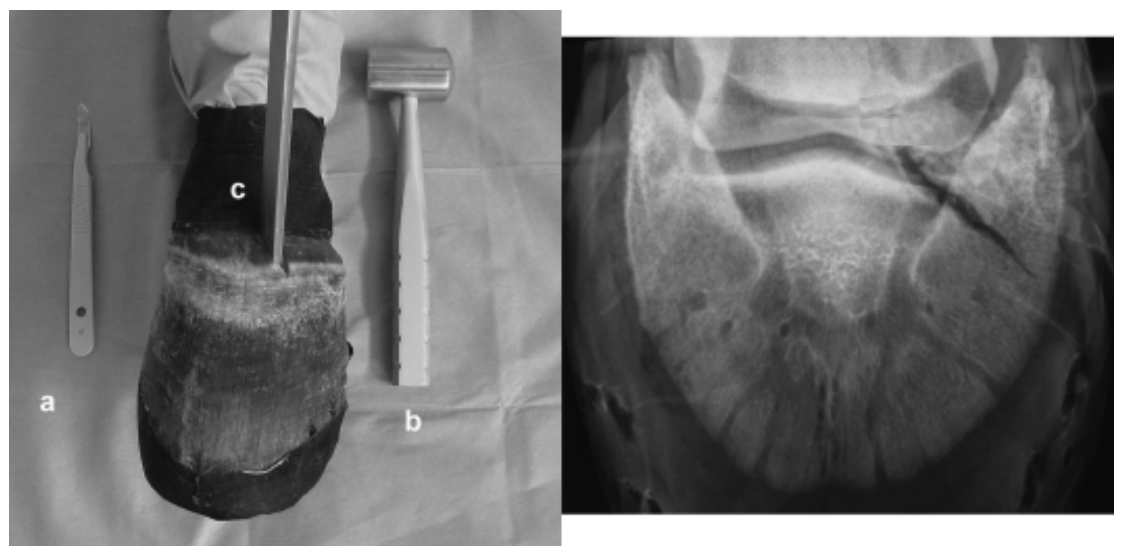

Fig 1. Left side: Preparation of an abaxial phalanx fracture in a cadaveric specimen using scalpel (a), mallet (b), and chisel (c). Right side: $60^{\circ}$ dorsoproximal-palmarodistal oblique radiographic view of an abaxial fracture prepared as shown above. Note the small abaxial fragment and the associated smaller dispersed fragments.

navigation technique. The DRB represents the basis for the $3 \mathrm{D}$ coordinate system in which preoperative planning occurs. After the limb was solidly fixed in lateral position onto a base consisting of carbon, the DRB was attached to the distal rim of the hoof capsule with a Schanz' screw to which the DRB was fixed and solidly tightened (Fig 2).

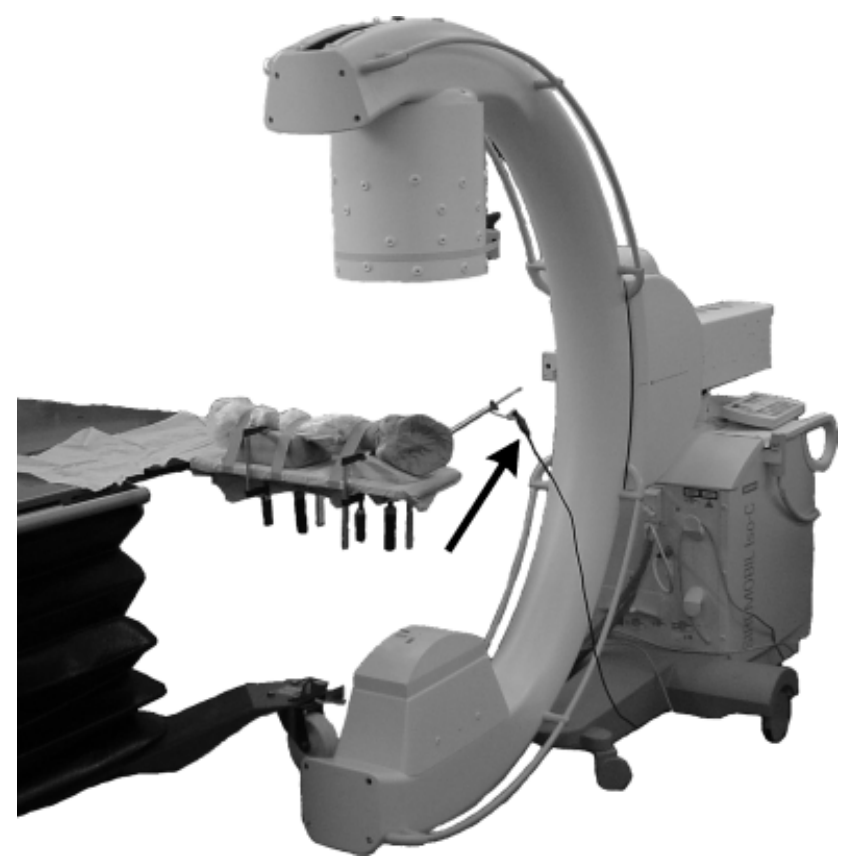

Fig 2. Overview of the surgical suite before taking the first data acquisition with the Siremobil Iso $C^{3 d}$. Note the limb fixed in laterolateral position on a carbon base support on the surgery table between the $\mathrm{C}$-arm of the Siremobil Iso $\mathrm{C}^{3 \mathrm{~d}}$. Black arrow: Dynamic Reference Base (DRB) with mounted LEDs applied to the distal rim of the hoof capsule with a Schanz screw. LED, light-emitting diode.
The data acquisition by the SIREMOBIL Iso- $\mathrm{C}^{3 \mathrm{~d}}$ was monitored from an adjacent room. A total of 100 radiographic images of the distal phalanx were taken over an arc of $190^{\circ}$ within a 2-minute period. The image intensifier subsequently processed all the images and assembled the data onto a cube having dimensions of $12.5 \times 12.5 \times 12.5 \mathrm{~cm}$.

The "syngo-calculator" of the image intensifier separated 256 single images from this cube and represented them in 3, 2D picture series, which were oriented perpendicular relative to each other. These data were then exported to the navigation system. All necessary instruments were also equipped with LEDs to allow their recognition by the navigation camera. With the help of the awl, the correct identification of any selected point on the hoof capsule was verified.

The orientation and desired location of the screw was marked on the computer screen using a mouse. Care was taken to ensure that the position was correctly displayed in 3 orthogonal planes (frontal-, parasagittal-, and cross-sectional planes) and then the data were saved and screw length calculated by the computer (Fig 3). Next, guidance navigation was applied to guide the drills and corresponding drill bits to prepare the required holes in the selected location and direction. Three circles representing the selected entry point on the hoof wall, the tip of the drill bit, and the LED mounted on the drill were visible on the screen. The surgeon subsequently oriented the drill so that the 3 circles were concentrically overlapping each other in all directions. Drilling was initiated under constant observation on the monitor to verify the concentric orientation of the 3 circles. A separate image on the navigation screen depicted the penetration of the drill bit into the hoof capsule and distal phalanx, respectively (Fig 4). Crossing of the artificially created fracture line and bone exit were easily recognized.

Once the screw was inserted and tightened, imaging data acquisition with the SIREMOBIL Iso- $\mathrm{C}^{3 \mathrm{~d}}$ was performed to verify screw position within the bone. These data were transferred to the navigation system. To assess accuracy of screw insertion relative to the preplanned position, it was necessary 


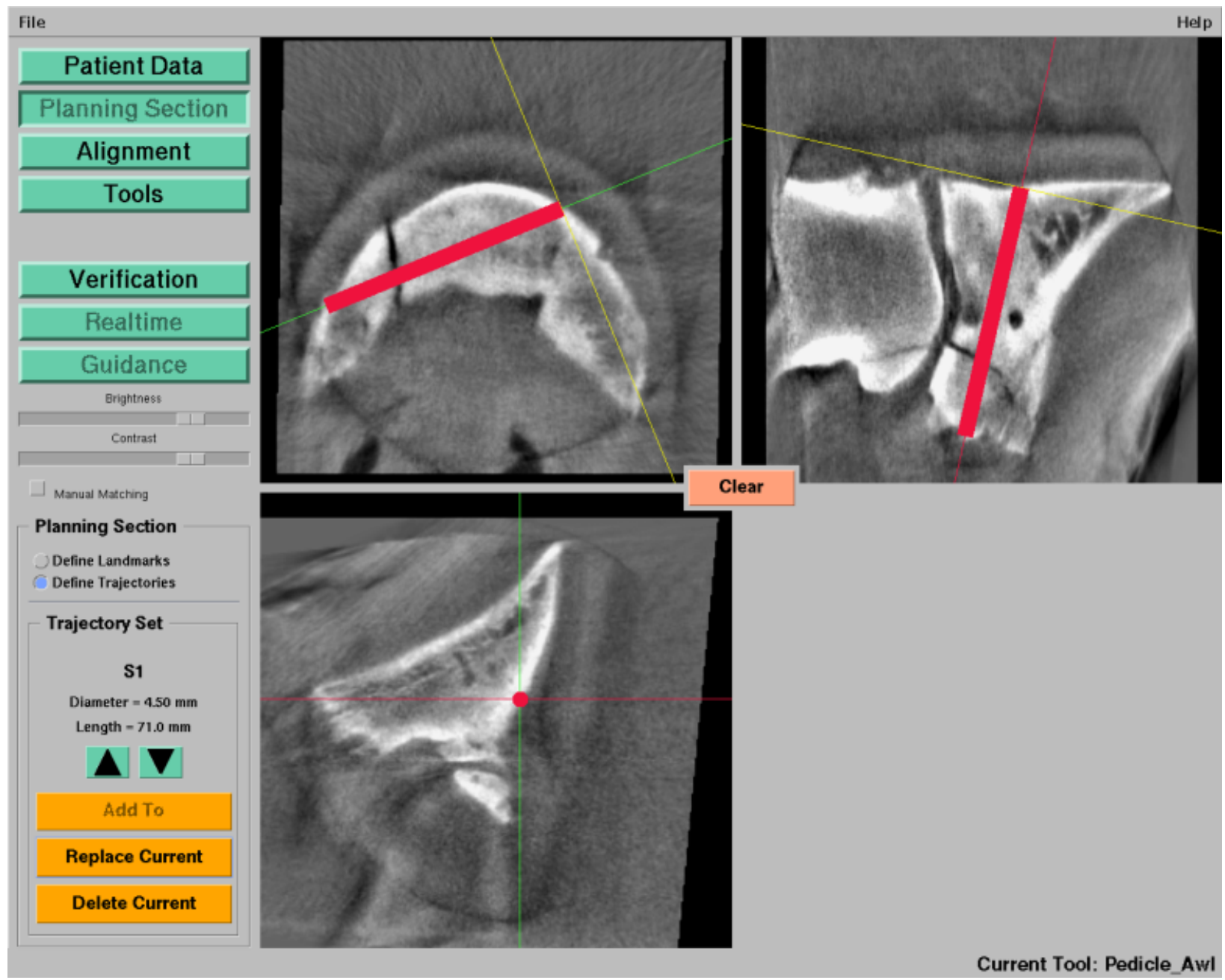

Fig 3. Screenshot of a planning session with computer-assisted surgery (CAS). The preplanned screw position is reflected by a red bar, the radiographic projections are: axial (top left), sagittal (top right), and the perpendicular plane of the distal phalanx at the level of the planned screw entry point (bottom). Screw size has to be selected by the surgeon before starting the planning session, the assumed length of the planned drill hole is evaluated by the CAS at the left side of the screen under trajectory set.

to superimpose the 2 coordinate systems and determine any aberration. This technique was used in each of the 8 limbs for both screw insertion directions.

\section{COS}

The COS technique was performed as described by Fackelman. ${ }^{16}$ The SIREMOBIL Iso- $\mathrm{C}^{3 \mathrm{~d}}$ was applied in $2 \mathrm{D}$ mode to identify the entry portal of the hoof wall and crossing of the fracture line. We modified the technique to ensure that implant placement was perpendicular to the fracture plane. To facilitate a perpendicular drilling direction relative to the fracture line, the image intensifier was positioned so that its laser identification lines were superimposed over the fracture line. The drill was then aimed perpendicular to the plane formed by the imaginary X-ray beam. Avoiding the semilunar canal with the drill could not be guaranteed because this structure is not visible during surgery. The length of the drill hole was determined by measuring the part of the drill bit inserted into the hoof and subtracting the thickness of the hoof wall. Because of countersinking, an additional $3 \mathrm{~mm}$ was deducted from the measurement to derive at the required screw length.

\section{Definition of Desired Screw Position}

In both groups, $4.5 \mathrm{~mm}$ cortex screws were to be inserted perpendicular to the artificially created fracture plane. Screws were to be located midway between the sole of the distal phalanx and the joint without penetrating the semilunar canal to avoid potential injury to the artery. Furthermore, the screw tips were not to protrude $>2 \mathrm{~mm}$ beyond the bone. Although screws of incorrect length would be replaced in clinical practice, for the purpose of this study for both CAS 

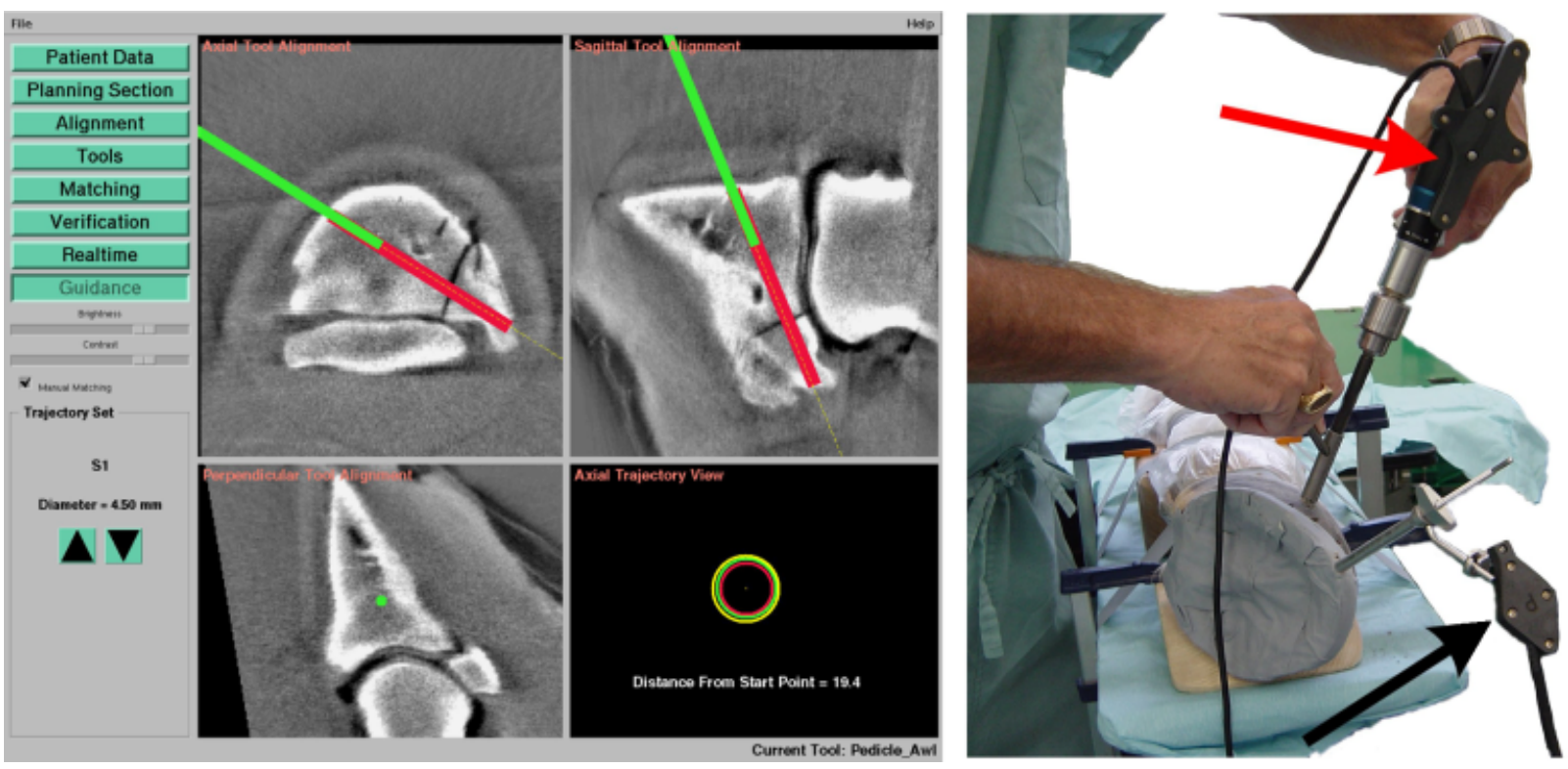

Fig 4. Navigation with CAS. Left side: Screen shot of a guidance procedure showing the virtual part of the procedure. A green beam depicts the projected direction of the drill bit preparing the glide hole across the parent portion of the bone along the preplanned screw direction. The fourth graphic (bottom right quadrant) depicts the entry point as a red circle, the tip of the drill bit as a green circle, and the Projection of the LED applied to drill as a yellow circle. Note the 3 circles are oriented concentrically, meaning that drilling is conducted along the center of the preplanned location. Right side: real navigated surgery in the operating room at the same time. The surgeon opens the hoof capsule by navigated drilling. Black arrow, Dynamic Reference Base (DRB), applied to the distal rim of the hoof capsule with the help of a Schanz screw; Red arrow, LED mounted on the drilling machine; CAS, computer-assisted surgery; LED, light-emitting diode.

and COS techniques, screws were inserted as planned and corrections were not permitted after fluoroscopic evaluation so that the initial accuracy of both techniques could be assessed.

\section{Postoperative Evaluation of the Distal Phalanx}

After implantation, the distal phalanges were exungulated, using the technique of Ossent and Lischer. ${ }^{21}$ Screw entry and exit points were examined and screw protrusion beyond either surface measured. Any damage caused by the screw (e.g. exit through the solar surface or joint, etc.) was recorded. The distal phalanx was photographed from multiple directions before screw removal. To evaluate potential penetration of the semilunar canal, the bone was separated at the solar foramen on the fracture side using a saw. Photographs of the exungulated distal phalanges were shown for clinical assessment to an experienced surgeon unaware of specimen grouping.

\section{Data Analysis}

Quality of Screw Positioning in Relation to Predetermined Parameters. Differences between groups for damage to the articular surface, violation of the semilunar canal, protrusion of screw tip, maximum torque applied to the screw, and ab- erration of clinical variables were analyzed using Fisher's exact test.

Maximal Precision of Screw Positioning Using CAS. The automatically stored coordinates of the entry and exit points determined during preoperative planning were superimposed over the coordinates of the screw axis to allow comparison of axial and angulation differences.

Preferred Screw Direction. Results of the summarized clinical analysis of screw positioning and of torque measurements were compared for different screw insertion directions. Data were compared separately for CAS and COS. Torque measurements were evaluated by Student's t-test. Statistical significance was set at $P<.05$.

\section{RESULTS}

Quality of Screw Positioning in Relation to Predetermined Parameters (Table 1, Fig 5)

A significant difference between CAS and COS was identified for involvement of the semilunar canal $(P<.001)$, screw tip protrusion $(P=.03)$, torque $(P<.001)$ and clinical assessment of screw position $(P<.001)$. There was no significant difference between CAS and COS for involvement of the articular $(P=.17)$ and solar surfaces $(P=.05)$. 
Table 1. Comparison of CAS and COS with Respect to Screw Positioning

\begin{tabular}{|c|c|c|c|c|c|}
\hline $\begin{array}{l}\text { Variable } \\
\text { Evaluated }\end{array}$ & Data & CAS & $\mathrm{COS}$ & Test & $\begin{array}{c}P- \\
\text { value }\end{array}$ \\
\hline \multirow[t]{2}{*}{$\begin{array}{l}\text { Articular } \\
\text { surface }\end{array}$} & None & 15 & 11 & $\begin{array}{c}\text { Fisher's } \\
\text { exact }\end{array}$ & .17 \\
\hline & Yes & 1 & 5 & & \\
\hline \multirow[t]{2}{*}{ Solar surface } & None & 16 & 12 & $\begin{array}{c}\text { Fisher's } \\
\text { exact }\end{array}$ & .05 \\
\hline & Yes & 0 & 4 & & \\
\hline \multirow[t]{2}{*}{$\begin{array}{l}\text { Semilunar } \\
\text { canal }\end{array}$} & None & 16 & 7 & $\begin{array}{c}\text { Fisher's } \\
\text { exact }\end{array}$ & $<.001$ \\
\hline & Yes & 0 & 9 & & \\
\hline \multirow[t]{2}{*}{$\begin{array}{l}\text { Screw tip } \\
\text { protrusion }\end{array}$} & $<2 \mathrm{~mm}$ & 12 & 5 & $\begin{array}{c}\text { Fisher's } \\
\text { exact }\end{array}$ & .03 \\
\hline & $>2 \mathrm{~mm}$ & 4 & $10^{*}$ & & \\
\hline Torque & Mean & $28.75 \mathrm{ckp}$ & $7.47 \mathrm{ckp}$ & $\begin{array}{c}\text { Student } \\
\text { t-test }\end{array}$ & $<.001$ \\
\hline \multirow{2}{*}{$\begin{array}{l}\text { Clinical } \\
\quad \text { analysis of } \\
\text { screw } \\
\text { position }\end{array}$} & $\begin{array}{l}\text { None to } \\
\text { minimal }\end{array}$ & 12 & 0 & $\begin{array}{c}\text { Fisher's } \\
\text { exact }\end{array}$ & $<.001$ \\
\hline & $\begin{array}{l}\text { All other } \\
\text { aberrations }\end{array}$ & 4 & 16 & & \\
\hline
\end{tabular}

* Limb 15 (COS) could not be used for the evaluation because it was for most of its length located within the hoof capsule and not in the distal phalanx.

CAS, computer-assisted surgery; COS, conventional osteosynthesis.

\section{Maximal Precision of Screw Positioning Using CAS (Table 2)}

Because of a recording error, 4 limbs could not be included in the comparison. From the remaining data, a mean discrepancy of angulation angle of $1.3^{\circ}$ (range, 0.4 $2.2^{\circ}$ ) was calculated. Mean difference in screw entry point was $3.1 \mathrm{~mm}$ (range, $0.9-4.6 \mathrm{~mm}$ ) whereas screw exit point had a mean difference of $3.1 \mathrm{~mm}$ (range, 0.4-5.6 mm). Mean percentage sharing of bone volume between planned and actual screw insertion was 26.9\% (range, $0-67.1 \%$ ).

\section{Preferred Screw Direction (Table 3)}

We were unable to determine a preferred screw insertion direction.

\section{DISCUSSION}

\section{Quality of Screw Positioning in Relation to Predetermined Parameters}

In an earlier study of induced axial fractures of the distal phalanx repaired by COS and CAS techniques, articular damage occurred in 2 limbs in the COS group and none treated by CAS. ${ }^{18}$ Although statistically not significantly different, likely because of small sample size, involvement of the articular surface occurred more commonly with the COS technique (5 instances; Table 1 ) than with CAS (1 instance). The higher frequency of articular involvement with abaxial fracture repair likely reflects a more complex screw orientation, a smaller margin for insertion error because of much smaller fragment size, and more difficult translation of complex spatial relations into clinical manipulations. Collectively, these reasons and others have contributed to reluctance to surgically repair abaxial fractures of the distal phalanx.

Penetration of the solar surface occurred in 4 limbs in the COS group compared with none in the CAS group (Table 1); however, the difference was not statistically significant. Avoiding penetration of the semilunar canal was one of our study objectives because it required increased precision of screw insertion. Clinically, the vessels within the semilunar canal are most likely injured at time of fracture, so avoiding penetration of the semilunar canal may be of lesser clinical importance. Although, we avoided penetration of the semilunar canal with CAS, there were 9 instances of damage with the COS technique. This outcome was anticipated because it was not possible to localize the semilunar canal without a sophisticated guidance system.

Protrusion of screw tip was considered poor for 4 screws inserted by CAS and for 10 screws inserted by COS (Table 1, Fig 5). Screws were not replaced as would occur in clinical practice, because we were interested in establishing the accuracy of screw length determination on first attempt by both methods. In an earlier study of axial fractures, screw replacement to simulate clinical practice, was allowed before measurement of screw protrusion, which resulted in less difference between techniques ${ }^{18}$ compared with the current study.

One of the screws barely penetrated the bone and was located mainly within the hoof wall, which clearly demonstrated the difficulties encountered in screw placement with COS. Postoperative use of SIREMOBIL Iso-C ${ }^{3 \mathrm{~d}}$ data acquisition assists in evaluation of screw length because tangential views can be easily assessed on the monitor. $^{22-25}$ Conventional fluoroscopy is more timeconsuming. Screws penetrating the sensitive laminae and hoof wall are irritating and cause lameness, resolution of which typically requires screw removal. ${ }^{4,5,7,9,14}$ In human surgery, CAS screw implantation is mainly used in the spine. Various studies comparing CAS and COS clearly show better results with CAS. ${ }^{22,26-32}$ Most screw placement errors were in screw length rather than orientation. Such mistakes occurred also with CAS but were attributed to poor verification of the match between the digital database and real time navigation, which has to be verified before onset of the surgical procedure ${ }^{27,28,33,34}$; however, there are also reports of no or only minimal differences between CAS and COS. ${ }^{34,35}$ 

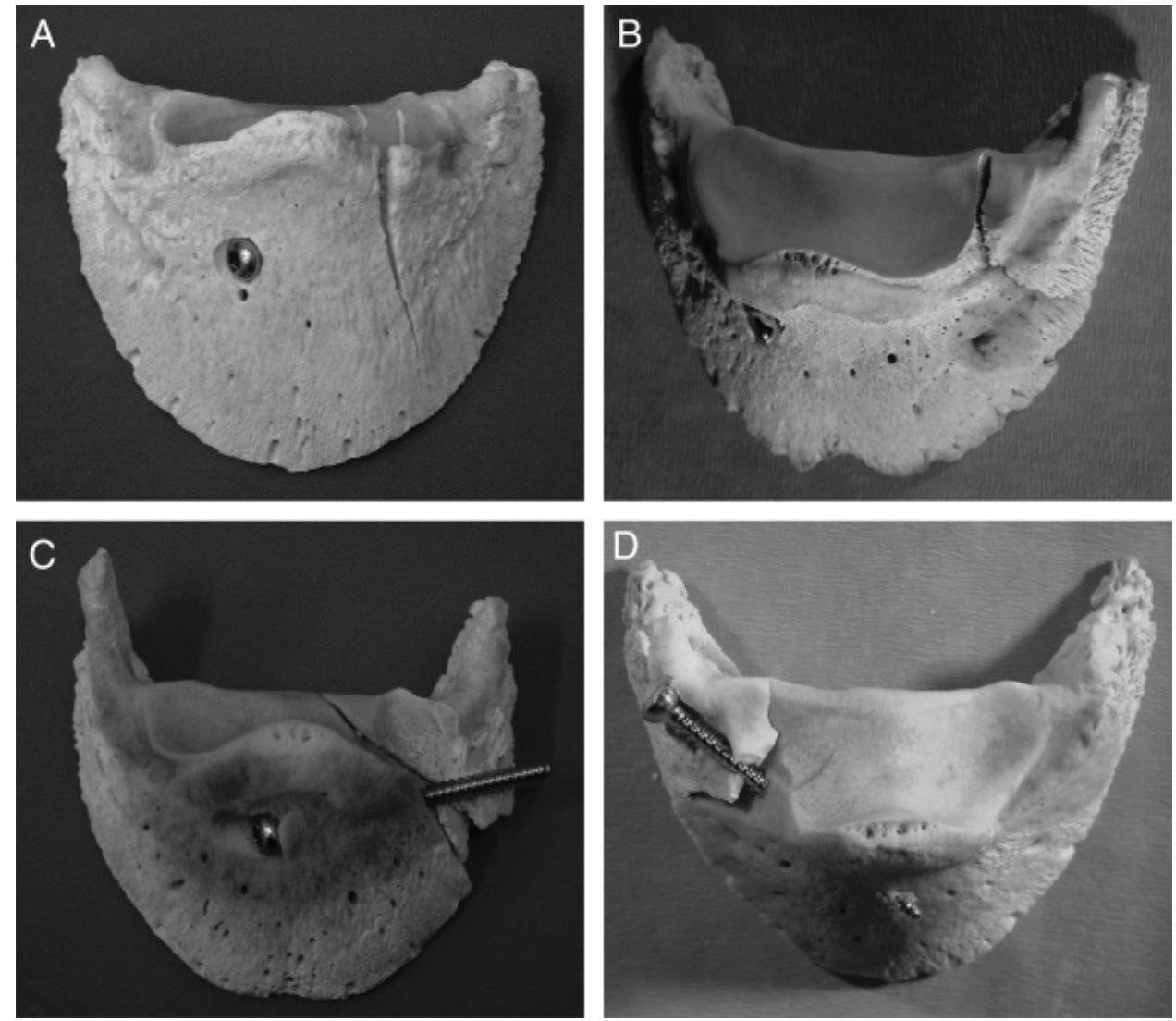

Fig 5. Gross specimens after exungulation. The artificial fracture created in each of the 4 specimens depict a wide variety. The top 2 consist of 1 main fragment, whereas in the bottom 2 in each, a small piece of bone is missing (multifragment fractures). (A) good fixation of an incomplete fracture with the COS technique; (B) good fixation of a complete fracture with the CAS technique; (C) poor result with the COS technique (excessive countersinking and excessively long screw penetrating the hoof wall, a lag effect was present but the proximal fragment fell out); (D) the worst result of the CAS technique groups (the palmarodorsal screw only partially penetrated the fragment but crossed the main fracture plane at about a right angle; the proximal fragment fell out). CAS, computer-assisted surgery; COS, conventional osteosynthesis.

A high torque level is an indication of a strong interfragmentary compression, which contributes to faster fracture healing. ${ }^{36,37}$ In our study, the achievable torque value was proportional to the thread hole length because all other variables related to torque were constant. With CAS it was possible to select a screw position with maximum thread-hole length in relation to the fragment size, thus contributing to significantly higher torque levels.

More than two-thirds of the limbs in the COS group had major errors which reinforces the clinical practice of conservative management of abaxial fractures of the distal phalanx. Use of CAS substantially improved precision of screw placement and minimized surgical error compared with COS (Fig 5). Solid fracture fixation and interfragmentary compression leads to faster and more complete bone healing. Our in vitro study clearly demonstrates the superiority of CAS over COS for surgical repair of abaxial fractures of the distal phalanx in horses.
Given the high error rate with COS, it would seem that if CAS is not available, conservative treatment including stall confinement and corrective shoeing should be the preferred method of treatment.

\section{Maximal Precision of Screw Positioning Using CAS}

Considerable variation in screw insertion precision is evident in reports of CAS use in human surgery. $22,23,31,38-$

${ }^{51}$ Positional errors range from $0.1 \mathrm{~mm}$ for deviation and $0.1^{\circ}$ rotational error ${ }^{23}$ to $6^{\circ}$ rotational error ${ }^{46}$ and deviation of $4.5 \mathrm{~mm} .{ }^{49}$ Gaultier et a ${ }^{51}$ using the same system (Medivision) for fixation of the human sacroiliac had a mean translational error of $2.7 \mathrm{~mm}$ (range, $0.4-6.3 \mathrm{~mm}$ ) for entry points, $3.5 \mathrm{~mm}$ (range, $0.2-8.2 \mathrm{~mm}$ ) for target points, and a mean angular deviation of $2^{\circ}$ (range, 0.4 $3.9^{\circ}$ ), results similar to ours. For the combination of the SurgiGATE 2.1 program and the SIREMOBIL Iso $\mathrm{C}^{3 \mathrm{~d}}$, 
Table 2. Differences Between Preplanned and Actual Screw Location

\begin{tabular}{|c|c|c|c|c|}
\hline $\begin{array}{l}\text { Screw Direction Limb } \\
\text { Number }\end{array}$ & $\begin{array}{l}\text { Deviation } \\
\text { (degrees) }\end{array}$ & $\begin{array}{l}\text { Difference-Planned } \\
\text { and Actual Entry Point (mm) }\end{array}$ & $\begin{array}{c}\text { Difference-Planned } \\
\text { and Actual Exit Point (mm) }\end{array}$ & $\begin{array}{c}\text { Volume } \\
\text { Ratio* }(\%)\end{array}$ \\
\hline \multicolumn{5}{|l|}{ Dorsopalmar/plantar } \\
\hline 1 & 2.2 & 2.6 & 5.6 & 8.2 \\
\hline 2 & 1.2 & 3.3 & 4.3 & 7.7 \\
\hline 3 & $\dagger$ & $\dagger$ & $\dagger$ & $\dagger$ \\
\hline 4 & 0.5 & 0.9 & 1.5 & 64.2 \\
\hline 5 & 1.2 & 2.3 & 2.7 & 33.7 \\
\hline 6 & 1.0 & 4.7 & 4.6 & 0 \\
\hline 7 & 1.5 & 4.7 & 4.3 & 0.7 \\
\hline 8 & $\dagger$ & $\dagger$ & $\dagger$ & $\dagger$ \\
\hline \multicolumn{5}{|l|}{ Palmaro/plantarodorsal } \\
\hline 9 & $\dagger$ & $\dagger$ & $\dagger$ & $\dagger$ \\
\hline 10 & 1.3 & 3.5 & 2.7 & 21.2 \\
\hline 11 & 1.2 & 1.8 & 1.5 & 60.0 \\
\hline 12 & 0.4 & 3.3 & 3.1 & 17.0 \\
\hline 13 & 0.8 & 4.6 & 4.8 & 0 \\
\hline 14 & 1.7 & 2.1 & 0.4 & 67.1 \\
\hline 15 & 2.0 & 3.0 & 1.1 & 43.1 \\
\hline 16 & $\dagger$ & $\dagger$ & $\dagger$ & $\dagger$ \\
\hline Mean & 1.3 & 3.1 & 3.1 & 26.9 \\
\hline
\end{tabular}

*Difference between volume shared by the planned and the actual trajectories and the sum of the volumes of both trajectories.

$\dagger$ Because of data recording error, these limbs could not be included in the analysis.

a system specific error $\leq 1.2 \mathrm{~mm}$ has been determined with consistent reproducibility. ${ }^{22}$ Errors of $1.74 \mathrm{~mm}$ $27,29,32$ in combination with $2 \mathrm{~mm}$ segments and $0.7 \mathrm{~mm}$ in combination with $1 \mathrm{~mm}$ segments have been published $^{29}$ with use of a CT unit. Despite the fact that our clinical results are promising and our precision analysis proved to be within the range of already published data from human surgery, ${ }^{22,23,31,38-51}$ we had expected a better outcome.

Conformity to virtual reality is the basic precision requirement of CAS. Deviation in the distance of $2.20 \mathrm{~m}$ between DRB and camera implies loss of precision. ${ }^{52}$ Registration and verification of an awl equipped with LEDs placed on a location, which can be recognized on the computer monitor in the 3 orthogonal planes is one of the most important steps assuring precision. ${ }^{34}$ After exchanging drill bits, etc. verification of every new instrument has to be completed to ensure calibration and frequent repetition of the localization process is recommended during surgery.

Table 3. Preferred Screw Direction: Palmaro-/Plantarodorsal Versus Dorsopalmar/-Plantar

\begin{tabular}{lcc}
\hline $\begin{array}{l}\text { Criterion Considered } \\
\text { Subdivision }\end{array}$ & $\begin{array}{c}\text { Torque } \\
\text { (Student t-Test) }\end{array}$ & $\begin{array}{c}\text { Clinical Assessment } \\
\text { of Screw Position } \\
\text { (Fisher's Exact Test) }\end{array}$ \\
\hline CAS & $P=.3$ & $P=.47$ \\
COS & $P=.12$ & $P=.57$ \\
\hline
\end{tabular}

CAS, computer-assisted surgery; COS, conventional osteosynthesis.
One of the largest contributors to relative inaccuracy is the anatomic location for screw insertion. In this location, especially when the screws were inserted in a palmaro/plantarodorsal direction, minute deviation from the preplanned location resulted in considerable error because of the pointed shape of the palmar/plantar process of the distal phalanx. Furthermore, countersinking resulted in accessory deviations between the preplanned and actual entry points, which partially explains the less than expected precision. Selection of the diagnostic imaging system associated with the navigation system also has an important role in precision of screw placement. For example, reported frequencies for screw misplacement in human spine, pelvis, and long bones with different imaging techniques were ${ }^{22}$ : COS $10.3 \%$, CAS in combination with CT $4.5 \%$, CAS in combination with 2D fluoroscopy $2.8 \%$, and CAS in combination with the SIREMOBIL Iso $\mathrm{C}^{3 \mathrm{~d}} 0.9 \%$.

Surgical skills and experience of the surgeon were also considered important factors. ${ }^{34} \mathrm{CAS}$ is working in a way that an LED positioned on the top of the drill transfers the drill bit into a virtual world on the computer screen. The SurgiGATE software projects the drill bit parallel to the axis of the drill. If the drill bit is not solidly fixed inside the drill chuck discrepancies can occur. We used a quick coupling system (Synthes Inc., Solothurn, Switzerland) which allows minimal movement between the drill bit and drill. This movement is not transferred to the computer screen resulting in a mismatch of conformity between virtual and real world. 
Pressure applied during drilling may lead to minimal bending of the drill bit, which in itself may cause discrepancies in real time navigation. ${ }^{35,53}$ Bending of the drill bit occurs more frequently if long narrow bits are used and if adjustments in alignment are forced after penetrating the bone, especially if the drill guide is not adjusted parallel with the drill bit. A bent drill bit cannot be displayed virtually which again leads to a mismatch between virtual and real world. Two possible solutions are use of additional LEDs directly applied to the drill guide or more rigid connection of the drill bit to the drill.

To achieve the lag screw principle, it is important that the screw cross the fracture plane in a perpendicular manner. If this cannot be achieved, tightening of the screw leads to fragment displacement, which results in step formation of the joint surface.

Perpendicular crossing of the fracture plane requires opening of the hoof capsule, which, when following the distal phalanx in a tangential way, causes additional precision problems. A $10 \mathrm{~mm}$ diameter, sharpened steel drill bit was used to open the hoof capsule. Exact verification of such an object is difficult because of its size and surface. The tangential approach to the convex hoof capsule surface makes concentric drilling nearly impossible. Similar to previous reports, the DRB was fixed to the hoof capsule. ${ }^{21,53}$ It can be assumed that the suspensory system of the distal phalanx is solid and prevents any relative movement between the capsule and the distal phalanx.

Our study clearly shows that improved precision can be achieved with CAS compared with COS; however, application of CAS to an abaxial fracture of the distal phalanx is not without risk and precaution to avoid inadvertent penetration of the joint must still be taken. Our results in the distal phalanx suggest that similar precision may be possible for osteosynthesis of the navicular bone $\mathrm{s}^{53}$ or spine.

\section{Preferable Screw Direction}

We had anticipated that the dorsopalmar/plantar direction would provide better results because of the increased bone-screw head contact surface after countersinking; however, analysis did not reveal a significant difference between screw directions (Table 3). Use of the palmaro-/plantarodorsal screw direction, allows increased length of the thread-hole which leads to higher torque levels. Additionally, the thread-hole is positioned in bone of higher density enabling better screw purchase. The palmar/plantar processes of the distal phalanx causes difficulties in avoiding excessive countersinking and in offering sufficient resistance to the screw head. Clinically, this may lead to higher dynamic forces on the screw head with a smaller contact area with the surrounding bone, potentially resulting in bone lysis around the implant. Contacting the small bone surface at the palmar/plantar process of the distal phalanx with the drill bit requires a high level of surgical skill. Despite the lack of significant difference between the 2 screw directions the dorsopalmar/-plantar screw direction is preferred because of the mechanically preferred position of the screw head on the dorsolateral/-medial aspect of the distal phalanx.

\section{ACKNOWLEDGMENTS}

We thank Oliver Rossol for statistical analysis; Jens Brandt for his patient support in solving mathematical and technical problems relating to precision analysis and for creating the lay-out; Götz Herrmann for technical support and recalibration of the CAS-System; Beatus Bächi for translating the first case report of surgery treatment of an abaxial distal phalanx fracture from Danish to German; Albert Weber, mechanical engineering, ETH Zurich for loan of the torque-assessing screw driver; Freddy Hohl, technical staff of the Equine Hospital of the University of Zurich for providing all screws and instruments; and Urs Müller and Bruno Gerzner, for their invaluable support during collecting, dissecting, and evaluating the limbs.

\section{REFERENCES}

1. Scott EA, Mc Dole M, Shires MH, et al: Fractures of the third phalanx (P3) in the horse at the Michigan State University, 1964-1979. Proc Am Assoc Equine Practnr 26:439450, 1980

2. Yovich JV, Hilbert BJ, Mc Gill CA: Fractures of the distal phalanx in horses. Aust Vet J 59:180-182, 1982

3. Stashak TS: Fractures in the Distal (Third) Phalanx (Pedal Bone, Os Pedis, Coffin Bone), in Stashak TS (ed.): Adam's Lameness in Horses (ed 5). Philadelphia, PA, Lea \& Febiger, 2002, pp 690-697

4. Rick CM: Fractures of the distal phalanx, in White NA, Moore JN (eds): Current Practice of Equine Surgery. Philadelphia, PA, Lippincott Company, 1990, pp 598-602

5. Honnas CM, Vacek JR, Schumacher J: Diagnosis and treatment of articular fractures of the equine distal phalanx. Vet Med 87:1208-1214, 1992

6. Rose RJ, Taylor BJ, Bellenger CR: Internal fixation of fractures of the third phalanx in three horses. Aust Vet J 55:2932, 1979

7. Gabel AA, Bukowiecki CF: Fractures of the phalanges. Vet Clin North Am Equine Pract 5:233-260, 1983

8. Bertone AL: Fracture of the distal phalanx, in Nixon AJ (ed): Equine Fracture Repair (ed 1). Philadelphia, PA, Saunders, 1996, pp 146-152

9. Auer JA: Fractures of the distal phalanx, in Colahan PT, Mayhew IG, Meritt AM, et al: (eds): Equine Medicine and Surgery, Vol 2 (ed 5). Philadelphia, PA, Mosby, 1999, pp 1500-1506 
10. Petterson $\mathrm{H}$ : Conservative and surgical treatment of fractures of the third phalanx. Proc Am Assoc Equine Practnr 18:183-192, 1972

11. Petterson H: Fractures of the pedal bone in the horse. Equine Vet J 8:104-109, 1976

12. Sonnichsen HV: Fraktur af hovben-Kasuistik meddelelse. Nord Vet Med 21:37-40, 1969

13. Fackelmann GE: Screw fixation of sagittal fractures of the third phalanx in horses. Vet Med Small Anim Clin 96:1317-1324, 1974

14. Yovich JV: Fractures of the distal phalanx in the horse. Vet Clin North Am Equine Pract 5:145-160, 1989

15. Fürst AE: Fractures of the distal phalanx, in Auer JA, Stick JA (eds): Equine Surgery (ed 3). St. Louis, MO, Saunders Elsevier, 2006, pp 1201-1206

16. Fackelmann GE: Distal phalanx, axial fractures, abaxial fractures, in Fackelmann GE, Auer JA, Nunamaker DM (eds): AO Principles of Equine Osteosynthesis. Stuttgart, Thieme Verlag, 2000, pp 115-124

17. Moyer W: Distal phalanx fractures. Proceedings, Refresher Course for Veterinarians: Equine Lameness and Foot Conditions. The University of Sydney Post-Graduate Foundation of Veterinary Science, Sydney Vol. 30:247, 1990

18. Andritzky J, Rossol M, Lischer CJ, et al: Comparison of computer assisted surgery with conventional technique for the treatment of axial distal phalanx fractures in horses: an in-vitro study. Vet Surg 34:120-127, 2005

19. Scott EA, Mc Dole M, Shires MH: A review of third phalanx fractures in the horse: sixty-five cases. J Am Vet Med Assoc 174:1337-1343, 1979

20. Nunamaker DM: General techniques and biomechanics, in Fackelmann GE, Auer JA, Nunamaker DM (eds): AO Principles of Equine Osteosynthesis. Stuttgart, Thieme Verlag, 2000, pp 11-16

21. Ossent P, Lischer C: Postmortem examination of the hooves of cattle, horses, pigs and small ruminants under practice conditions. In Pract 19:21-29, 1997

22. Grützner PA, Hebecher A, Waelti H, et al: Klinische Studie zur registrierungsfreien 3D-Navigation mit dem mobilen CBogen SIREMOBIL Iso-C 3d. Electromedica 71:58-67, 2003

23. Sikorski JM, Chauhan S: Computer-assisted orthopaedic surgery: do we need CAOS? J Bone Joint Surg Br 85:319 323, 2003

24. Euler E, Heining S, Riquarts C, et al: C-arm based threedimensional navigation: a preliminary feasibility study. Comp Aided Surg 8:35-41, 2003

25. Euler E, Heining S, Fischer $\mathrm{T}$, et al: Erste klinische Erfahrungen mit dem Siremobil Iso-C 3d. Electromedica 70:64-67, 2002

26. Amiot LP, Lang K, Patzier M, et al: Comparative results between conventional and computer assisted pedicle screw installation in the thoracic, lumbar and sacral spine. Spine 25:606-614, 2000

27. Laine T, Schlenzka D, Mäkitalo K, et al: Improved accuracy of pedicle screw insertion with computer assisted surgeryA prospective clinical trial of 30 patients. Spine 22:1254 1258,1997
28. Laine T, Lund T, Ylikoski M, et al: Accuraccy of pedicle screw insertion with and without computer assistance: a randomised controlled clinical study in 100 consecutive patients. Eur Spine 9:235-240, 2000

29. Langlotz F, Nolte LP: Image guided spine surgery. Min Invas Ther Allied Technol 8:291-296, 1999

30. Peters P, Langlotz F, Nolte LP: Computer assisted screw insertion into real $3 \mathrm{D}$ rapid prototyping pelvis models. Clin Biomech 17:376-382, 2002

31. Caversaccio M, Nolte LP, Häusler R: Present state and future perspectives of computer aided surgery in the field of ENT and skull base. Acta Otorhinolaryngol Belg 56:51-59, 2002

32. Schlenzka D: Klinische Erfahrungen bei der Anwendung eines Navigationssystems in der Wirbelsäulenchirurgie. Trauma Berufskrankh 1:116-119, 1999

33. Schep NWL, Broeders IAMJ, van der Werken C: Computer assisted orthopaedic and trauma surgery-State of the art and future perspectives. Injury 34:299-306, 2003

34. Arand M, Hartwig E, Hebold D, et al: Präzisionsanalyse navigationsgestützt implantierter thorakaler und lumbaler Pedikelschrauben-Eine prospektive klinische Studie. Unfallchirurg 104:1076-1081, 2001

35. Suhm N, Jacob LA, Zuna I, et al: Fluoroskopiebasierte chirurgische Navigation versus mechanisches Zielsystem für perkutane Eingriffe - Eine kontrollierte prospektive Studie am Beispiel der distalen Verriegelung von Marknägeln. Unfallchirurg 106:921-928, 2003

36. Field JR: Screw torque and interfragmentary compression in equine cadaver longbone fractures. Vet Comp Orthop Traumatol 6:163-165, 1993

37. Johnson KA, Smith FW: Axial compression generated by cortical and cancellous lag screws in the equine distal phalanx. Vet J 166:159-163, 2003

38. Grevers G, Menauer F, Leunig A, et al: Navigationschirurgie bei Nasennebenhöhlenerkrankungen. Laryngorhinootologie 78:41-46, 1999

39. Rombaux P, Ledeghen S, Hamoir M, et al: Computer assisted surgery and endoscopic endonasal approach in 32 procedures. Acta otorhinolaryngol Belg 57:131-137, 2003

40. Chassat F, Lavallee S: Experimental protocol of accuracy evaluation of $6 \mathrm{D}$ localizers for computer integrated surgery: application to four optical localizers, in Wells WM, Colchester A, Delp S (eds): Proceedings of 1st International Conference on Medical Image Computing and Computer Assisted Interventions (MICCAI'98) Cambridge, MA, October 1998. Berlin, Springer, 1998, pp 277-284

41. Li Q, Zamorano L, Jiang Z, et al: The application accuracy of the frameless implantable marker system and analysis of related affecting factors, in Wells WM, Colchester A, Delp $\mathrm{S}$ (eds): Proceedings of 1st International Conference on Medical Image Computing and Computer Assisted Interventions (MICCAI'98) Cambridge, MA, October 98. Lecture Notes in Computer Science 1496. Berlin, Springer Verlag, 1998, pp 253-260

42. Zylka W, Sabczynski J: Effect of localization devices and registration methods on the accuracy of stereotactic frame 
systems predicted by the Gaussian approach. Comp Aid Surg 4:77-86, 1999

43. Caversaccio M, Ladrach K, Bächler R, et al: Computer assisted surgical navigation with a dynamic mobile framework for the nasal fossae, sinuses and base of the skull. Ann Otolaryngol Chir Cervicofac 115:253-258, 1998

44. Sasama T, Nakahodo K, Ohzono K, et al: Accuracy evaluation in computer assisted hip surgery, in Lemke HU, Vanier MW, Inamura K, et al: (eds): Computer aided radiology and surgery: Proceedings of the $13^{\text {th }}$ International congress and exhibition (CARS 99) Paris June 1999. Amsterdam, Elsevier, 1999, pp 772-776

45. Hassfeld S, Burghart C, Bertovic I, et al: Intraoperative navigation techniques: Accuracy tests and clinical report, in Lemke HU, Vanier MW, Inamura K, Farman AG (eds): Computer aided radiology and surgery: Proceedings of the $13^{\text {th }}$ International congress and exhibition (CARS 99) Paris June 1999. Amsterdam, Elsevier, 1999, pp 670-675

46. Glossop ND, Hu RW, Randle JA: Computer-aided pedicle screw placement using frameless stereotaxis. Spine 21:2026-2034, 1996
47. Nolte LP, Zamorano LJ, Langlotz F, et al: A novel approach to image guided spine surgery. SPIE Visual Biomed Comp 2359:564-573, 1994

48. Carl AL, Khanuja HS, Sachs BL, et al: In vitro simulation. Early results of stereotaxy for pedicle screw placement. Spine 22:1160-1164, 1997

49. Amiot LP, Labelle H, De Guise JA, et al: Computer assisted pedicle screw fixation. A feasibility study. Spine 20:12081212, 1995

50. Langlotz F, Stucki M, Bächler R, et al: The first twelve cases of computer assisted periacetabular osteotomy. Comput Aided Surg 2:317-326, 1997

51. Gautier E, Bächler R, Heini PF, et al: Accuracy of computerguided screw fixation of the sacroiliac joint. Clin Orthop Relat Res 393:310-317, 2001

52. Khadem R, Yeh CC, Sadeghi-Tehrani M, et al: Comparative tracking error analysis of five different optical tracking systems. Comp Aided Surg 5:98-100, 2000

53. Gygax D, Lischer CJ, Auer JA: Computer-assisted surgery for screw insertion into the distal sesamoid bone in horses: an in vitro study. Vet Surg 35:626-633, 2006 



\section{Lebenslauf}

Name Melanie Rossol

Geburtsdatum $\quad$ 18.12.1975

Geburtsort Gehrden

Nationalität deutsch

1982-1986

Grundschule Weetzen

1986-1988

Orientierungsstufe Ronnenberg

1988-1995

Matthias-Claudius-Gymnasium Gehrden, Abitur

1995-1996 Freiwilliges Soziales Jahr/ Schwesternhelferin-Ausbildung

Robert-Koch-Krankenhaus Gehrden

1996-2002 Studium der Veterinärmedizin an der Tierärztlichen Hochschule

Hannover, Deutschland

08.07.2002 Staatsexamen an der Tierärztlichen Hochschule Hannover, Deutschland

2002-2003 Hospitanz und Vertretungstätigkeit Tierärztliche Praxis für Pferde, Dr. Constanze Leipold, Wennigsen, Deutschland

2002-2003 Wissenschaftliche Hilfskraft Anatomisches Institut der Tierärztlichen Hochschule Hannover, Deutschland

2003

Fellowship Departement Pferdechirurgie, Universität Zürich, Schweiz

2004-2008

Assistentin Tierarztpraxis Wolfgang Gabrin, Hofgut Albführen,

Dettighofen, Deutschland 
